\title{
Bimanual examination for clot evacuation: a retrospective cohort study of women with postpartum haemorrhage after vaginal delivery
}

Pui Ru Koh ${ }^{1}$, Daria Di Filippo ${ }^{1}$, Andrew Bisits ${ }^{2}$ and Alec W. Welsh ${ }^{1,3^{*}}$

\begin{abstract}
Background: Bimanual clot evacuation (BCE) is a simple clinical manoeuvre that may reduce need for surgical intervention in the management of severe postpartum haemorrhage (PPH). We sought to determine whether performing BCE in cases of severe PPH after vaginal birth reduces the need for surgical intervention.

Methods: A retrospective chart review of women who delivered vaginally with a severe PPH between January 1 , 2011 and December 31, 2014 in a single tertiary women's hospital in Sydney, Australia was conducted. Severe PPH was classified as a blood loss $\geq 1000 \mathrm{mls}$. The need for surgical management (including operating theatre uterine exploration or evacuation, intrauterine balloon tamponade, repair of significant trauma, uterine or internal iliac artery ligation, B-Lynch suture insertion or hysterectomy) was the primary outcome measure, as expressed by need for operating theatre utilisation.

Results: From a cohort of 438, 149 women (34.0\%) had BCE, of whom 29 (19.5\%) required surgical management compared to 103 of 289 women with no BCE (35.6\%); an odds ratio (OR) of 0.38 for BCE (confidence interval 0.20$0.72 ; p=0.003)$. Early $B C E(<1 \mathrm{~h}$ of delivery) was associated with a further reduction in surgery (OR 0.24 ; confidence interval 0.08-0.70; $p=0.009$ ) compared to late $\mathrm{BCE}$ ( $>1 \mathrm{~h}$ of delivery). There was no reduction in estimated blood loss $(p=0.86)$ or blood transfusion ( $p=0.71$ ) with BCE.

Conclusion: Our study suggests BCE reduces theatre utilisation in the context of severe PPH following vaginal delivery. Prospective trials are needed to determine whether BCE should be endorsed as a treatment modality for $\mathrm{PPH}$ post-vaginal delivery.
\end{abstract}

Keywords: Postpartum haemorrhage, Uterine evacuation, Bimanual clot evacuation

\footnotetext{
* Correspondence: alec.welsh@unsw.edu.au

'School of Women's and Children's Health, University of New South Wales, Randwick, NSW, Australia

${ }^{3}$ Department of Maternal-Fetal Medicine, Royal Hospital for Women, Locked Bag 2000, Barker Street, Randwick, NSW 2031, Australia

Full list of author information is available at the end of the article
}

(c) The Author(s). 2020 Open Access This article is licensed under a Creative Commons Attribution 4.0 International License, which permits use, sharing, adaptation, distribution and reproduction in any medium or format, as long as you give appropriate credit to the original author(s) and the source, provide a link to the Creative Commons licence, and indicate if changes were made. The images or other third party material in this article are included in the article's Creative Commons licence, unless indicated otherwise in a credit line to the material. If material is not included in the article's Creative Commons licence and your intended use is not permitted by statutory regulation or exceeds the permitted use, you will need to obtain permission directly from the copyright holder. To view a copy of this licence, visit http://creativecommons.org/licenses/by/4.0/. The Creative Commons Public Domain Dedication waiver (http://creativecommons.org/publicdomain/zero/1.0/) applies to the data made available in this article, unless otherwise stated in a credit line to the data. 


\section{Background}

The World Health Organisation defines postpartum haemorrhage (PPH) as blood loss $>500 \mathrm{ml}$, or any amount resulting in haemodynamic instability after delivery [1]. Classified as severe if $\geq 1000 \mathrm{mls}$, PPH remains the leading global cause of maternal mortality and morbidity [2], causing 140,000 deaths per year [3]. Our own institution in Australia has previously reported a severe $\mathrm{PPH}$ rate of $4.7 \%$ [4]. Women with severe PPH may require intensive care unit (ICU) admission, surgical interventions for bleeding control (e.g. uterine evacuation, intrauterine balloon tamponade, repair of cervical lacerations and other trauma, or more invasive therapy such as uterine or internal iliac artery ligation, B-Lynch suture insertion or hysterectomy), and transfusion of blood products [5]. Because the rate of $\mathrm{PPH}$ has been increasing in well-resourced countries, attention has been focussed on strategies to improve how $\mathrm{PPH}$ is managed on labour and delivery units [6-8].

Arrest of bleeding in the immediate postpartum phase is related to the ability of the uterus to fully contract with myometrial fibres acting as 'physiological ligatures' on the blood supply to the placental bed. In addition to mechanical haemostasis, local haemostatic (tissue factor, type-1 plasminogen activator inhibitor) and systemic coagulation (platelets, circulating clotting factors) factors are also activated to induce haemostasis [7, 8]. Any space-occupying tissue (clot or retained placenta or membrane) may prevent full uterine contraction, with surgical intervention needed to control the bleeding. Bimanual clot evacuation (BCE) may be a viable surgical intervention. BCE involves 'cupping' the fundus of the uterus with one hand whilst performing a vaginal examination to digitally break down and expel any blood clots [9]. This is hypothesised to enhance the effect of uterotonic agents on myometrial tissue by facilitating emptying of the uterine cavity. This procedure, generally performed under maternal analgesia obtained with nitrous oxide or a pre-existing epidural, is traditionally taught by more senior obstetricians and midwives, though has received limited academic attention. Of four contemporary national College PPH guidelines from the United Kingdom (RCOG), United States of America (ACOG), Australia and New Zealand (RANZCOG), and Canada (SOGC), none discuss the role of BCE [10], though a previous SOGC Clinical Practice Guideline did describe use of an initial exploration of the uterus, without a clear description of BCE [11]. The 2012 World Health Organisation (WHO) recommendations do mention the role of a similar procedure, bimanual uterine compression, as a temporizing measure for $\mathrm{PPH}$ until further definitive management can be applied, however this is a distinctly different procedure to $\mathrm{BCE}$, where only physical pressure is applied for compression to aid haemostasis. Whilst this has shown potential benefit there are only a limited number of randomised controlled trials, with both a Cochrane
Systematic Review and a more recent systematic review and meta-analysis being inconclusive $[12,13]$.

End-points for PPH that may be used to evaluate efficacy of management include volume of blood loss with associated physiological compromise and need for advanced surgical procedures that may require operative intervention. Given the lack of published information on this commonly performed and relatively simple procedure, our primary aim was to compare rates of surgical intervention among women receiving vs not receiving $\mathrm{BCE}$ in the setting of severe $\mathrm{PPH}$ post-vaginal delivery.

\section{Methods}

A retrospective cohort study of management of severe $\mathrm{PPH}$ cases $(\geq 1000 \mathrm{mls})$ occurring between January 1, 2011 to December 31, 2014 at the Royal Hospital for Women in Sydney, Australia was undertaken. Ethics approval was obtained from the District Ethics Review Committee (13/076-LNR 13/POWH/418); all data were non-identifiable, and individual informed consent for participants was not required.

Participants were included in the study if they delivered vaginally, either spontaneous or assisted, and had severe $\mathrm{PPH}$ as defined by best obstetric estimate and quantitative blood loss where applied. Data was extracted from a state-wide obstetric clinical reporting system developed by the New South Wales (NSW) Department of Health Obstetrics Consortium ('ObstetriX'; Meridian Health Informatics, Sydney, Australia). 'ObstetriX 'is used in 13 NSW Local Health Districts and in 61 maternity facilities across NSW. It is responsible for almost $60 \%$ of the electronic submissions to the NSW Perinatal Data Collection, and provides other functionality which assists in the documentation of obstetric episodes of care and in other reporting to Public Health Units, enabling hospitals and NSW Health to meet their statutory reporting requirements electronically. The database was filtered to generate the medical record numbers of only women who delivered vaginally and had $\mathrm{PPH}>11$ during the study period. Maternal records of these women were then retrieved and manually reviewed for data collection. The lowest haemoglobin results were retrieved from the hospital computer pathology system using the generated medical record numbers ('Powerchart'; Cerner Inc., North Kansas, USA).

Data collected included socio-demographic and obstetric characteristics along with delivery, neonatal and PPH management details. Socio-demographic characteristics collected were maternal age, body mass index, and model of care (public or private). Obstetric characteristics included parity, gestation (single or multiple) and previous PPH. Delivery details included labour onset (spontaneous or induced), mode of birth (spontaneous or assisted vaginal delivery), gestational age, epidural usage, duration of 3rd stage, and total estimated blood loss. Neonatal details included birth weight. 
We undertook detailed physical review of clinical documentations regarding the management of $\mathrm{PPH}$, which included time of birth, time of medical notification and of actual medical review, time of bimanual clot evacuation (if performed), type, timing of and total dose of uterotonic agents, additional operative intervention, need for transfusion of blood products, and lowest postpartum haemoglobin level. The latter was used as a surrogate marker of blood loss, given the known inaccuracy of visual blood loss estimation $[14,15]$.

The primary outcome for this study was the rate of significant surgical intervention; including need for uterine exploration or evacuation, the use of intrauterine balloon tamponade, repair of significant uterine, cervical or vaginal trauma, uterine or internal iliac artery ligation, B-Lynch suture insertion or hysterectomy. Given the additional costs, disruption to the mother:baby unit and potential associated complications we chose to use operating theatre utilisation as our marker for 'significant' surgical intervention. Secondary outcome measures were total blood loss, need for blood transfusion, lowest haemoglobin $(\mathrm{Hb})$ level and use of uterotonic medications.

At this tertiary obstetrics referral hospital there were approximately 4200 births per year with a vaginal delivery rate of $70 \%$, equating to 2940 vaginal births in a year. Given an estimated frequency of $5 \%$ for severe $\mathrm{PPH}$, we anticipated approximately 150 women to undergo surgical intervention after PPH per year. Selecting surgical intervention as the primary outcome, and estimating that approximately one third of cases would have BCE, we calculated that a sample of 462 patients was needed for $90 \%$ power to detect a $50 \%$ difference from 25.0 to $12.5 \%$ at a 2 -sided alpha level of 0.05 , requiring study of cases over a 4 -year period. Statistical analysis was performed using SPSS version 23 (IBM Corp, Armonk, New York, United States), and STATA version 16 (StataCorp, College Station, TX) for multivariable logistic regression. Continuous outcomes were assessed by $\mathrm{t}$-test, or by multiple linear regression when there were potential confounding variables. Binary and categorical outcomes were assessed by Chi-squared test, or by logistic regression when there were potential confounding variables. The alpha level used for the tests is 0.05 .

A subgroup analysis was performed for those who underwent 'early' BCE (within $1 \mathrm{~h}$ of delivery) versus later $\mathrm{BCE}$, as we hypothesised that earlier emptying of the uterus would facilitate more effective use of other measures such as administration of uterotonic agents, thus reducing theatre utilisation.

\section{Study settings}

The study was carried out in the Royal Hospital for Women (Sydney), a level-6 quaternary referral hospital, which is also a major teaching hospital affiliated to the University of New South Wales (UNSW).

\section{Results}

There were 438 cases of severe PPH at the tertiary hospital between January 1, 2011 and December 31, 2014 (3.8\% of vaginal births). Of these, 149 women (34.0\%) underwent BCE. Socio-demographic, obstetric and birth characteristics are summarised in Table 1. Compared to those not receiving $\mathrm{BCE}$, women receiving $\mathrm{BCE}$ were slightly younger and were less likely to experience a third stage length longer than $30 \mathrm{~min}$.

Primary and secondary outcomes are summarised in Table 2. In our cohort of 438, 149 women (34\%) underwent BCE, while the remaining 289 (66\%) did not. In the BCE group, $19.5 \%$ needed surgery compared to $35.6 \%$ women without BCE (OR 0.38; 95\% CI 0.20-0.72; $p=$ 0.003). Of the 149 who had BCE, it was performed early in 104 women, and late in 45 women. Surgical intervention was required in 16 of the early BCE group (15.4\%), and in $13(28.9 \%)$ women who had it performed late (OR 0.24; 95\% CI 0.08-0.70; $p=0.009$ ).

Multivariate regression analysis was performed using surgical intervention as the dependent variable, and $\mathrm{BCE}$, the use of uterotonic agents, total blood loss and length of the third stage and primiparity as independent variables*. When analysed after adjusting for confounders, the difference between the 2 groups were still statistically significant. The goodness of fit test for this model using the Hosmer-Lemeshow test $(p=0.28)$ showed adequate fit.

BCE was not associated with a reduction in total blood loss $(p=0.86)$, blood transfusion $(p=0.71)$ or lowest postpartum haemoglobin $(p=0.36)$. The average time taken for medical officer notification was longer in the BCE group than in the non-BCE group (39.83 vs 17.78 $\min , p=0.003)$. The average times taken for actual medical review in the $\mathrm{BCE}$ and non-BCE groups following notification were 4.2 and $3.0 \mathrm{~min}$, respectively. There was no association between speed of attendance and the performance of $\mathrm{BCE}(p=0.47)$.

$$
\begin{aligned}
& * \pi(\text { surgicalmx }) / 1-\pi(\text { surgicalm } x) \\
& =\text { e } \alpha+\beta 1 B C E+\beta 2 \text { prostaglandins } \\
& \quad+\beta 3 \text { totalbloodloss }+\beta 4 \text { prolonged } 3 \text { rdstage } \\
& \quad+\beta 5 \text { ergometrine }+\beta 6 \text { primipar }
\end{aligned}
$$

A variety of surgical procedures were documented in the notes, as seen in Table 2. The commonest procedure was repair of genital tract trauma, occurring in 107 out of the 438 cases (24.4\%). Manual removal of placenta (MROP) was performed in $14.6 \%$ and uterine evacuation in $10.5 \%$. Other procedures used were: Bakri balloon $2.5 \%$; vaginal packing $0.5 \%$; vaginal haematoma drainage $0.5 \%$; bilateral uterine artery ligation, bilateral uterine artery embolization, hysterectomy and B-Lynch suture, each one case $(0.2 \%)$. Uterine evacuation, MROP and 
Table 1 Socio-demographic, obstetric and delivery details

\begin{tabular}{|c|c|c|c|c|c|}
\hline \multirow{2}{*}{\multicolumn{2}{|c|}{ 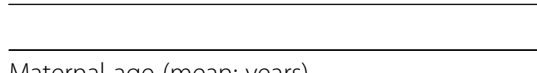 }} & Total cohort $(n=438)$ & BCE performed $(n=149)$ & BCE not performed $(n=289)$ & $p$ value $^{1}$ \\
\hline & Maternal age (mean; years) & 32.4 & 31.7 & 32.7 & 0.03 \\
\hline \multicolumn{2}{|l|}{$\mathrm{BMI}>30$} & $29(6.6 \%)$ & $10(6.7 \%)$ & $19(6.6 \%)$ & 0.89 \\
\hline \multicolumn{2}{|l|}{ Public care (\%) } & 95.4 & 95.3 & 95.5 & 0.92 \\
\hline \multicolumn{2}{|l|}{ Nulliparity } & $263(60.0 \%)$ & $82(55.0 \%)$ & $181(62.6 \%)$ & 0.12 \\
\hline \multicolumn{2}{|l|}{ Singleton pregnancy } & $427(97.5 \%)$ & $146(98.0 \%)$ & $281(97.2 \%)$ & 0.63 \\
\hline \multicolumn{2}{|l|}{ Previous PPH (\%) } & 7.5 & 8.1 & 7.3 & 0.77 \\
\hline \multicolumn{2}{|c|}{ Birth weight (mean; grams) } & 3570.4 & 3591.0 & 3559.8 & 0.60 \\
\hline \multicolumn{2}{|l|}{ Spontaneous labour } & $285(65.1 \%)$ & $100(67.1 \%)$ & $185(64.0 \%)$ & 0.52 \\
\hline \multicolumn{2}{|l|}{ Spontaneous birth } & $280(63.9 \%)$ & 99 (66.4\%) & $181(62.6 \%)$ & 0.47 \\
\hline \multirow[t]{3}{*}{ Delivery gestation: } & Preterm (<37 weeks) & $26(5.9 \%)$ & $5(3.4 \%)$ & $21(7.3 \%)$ & \multirow[t]{3}{*}{0.25} \\
\hline & Term (37-41 weeks) & $325(74.2 \%)$ & $117(78.5 \%)$ & $208(72.0 \%)$ & \\
\hline & Post-term (> 41 weeks) & 87 (19.8\%) & $27(18.1 \%)$ & $60(20.8 \%)$ & \\
\hline \multicolumn{2}{|c|}{ Prolonged 3rd stage (> $30 \mathrm{~min}$ ) } & $66(15.1 \%)$ & $10(6.7 \%)$ & $56(19.4 \%)$ & $<0.001$ \\
\hline
\end{tabular}

${ }^{1}$ Continuous variables were assessed by the t-test and categorical variables were analysed using the chi-squared test. $P$ value of $<0.05$ is considered statistically significant

repair of genital tract trauma were utilised more in the non-BCE group, reaching statistical significance $(p<$ $0.001)$.

Table 3 shows uterotonic drug usage following routine intramuscular Oxytocin and association with bimanual clot evacuation. Use of Ergometrine was statistically higher in the BCE than non-BCE groups (85.2 vs $56.4 \%$; $p<0.001)$. There were also significantly higher proportion of patients requiring additional ergometrine doses, misoprostol and PgF2 $\alpha$ in the BCE group. There was no statistically significant difference in the use of oxytocin infusion between the groups (100 vs $97.9 \%, p=0.10$ ). A sub-group analysis demonstrated that Oxytocin infusion administered after BCE was associated with a statistically significant, yet modest, reduction in blood loss (1419.5 vs $1676.7 \mathrm{ml}, p=0.001)$. Misoprostol given after BCE resulted in a statistically significantly higher haemoglobin level $(92.3$ vs $80.0 \mathrm{~g} / \mathrm{L} ; p=0.001)$. Misoprostol had a statistically significant influence on the lowest postpartum haemoglobin for those who received BCE (90.5 vs 96.2

Table 2 Primary and secondary outcomes

\begin{tabular}{|c|c|c|c|c|}
\hline & $\begin{array}{l}\text { Total Cohort } \\
(n=438)\end{array}$ & $\begin{array}{l}\text { BCE Performed } \\
(n=149)\end{array}$ & $\begin{array}{l}\text { BCE not performed } \\
(n=289)\end{array}$ & $p$ value \\
\hline Surgical intervention & $132(30.1 \%)$ & $29(19.5 \%)$ & $103(35.6 \%)$ & 0.003 \\
\hline Uterine evacuation & $46(10.5 \%)$ & $24(16.1 \%)$ & $22(7.6 \%)$ & 0.006 \\
\hline MROP & $64(14.6 \%)$ & $0(0 \%)$ & $64(22.1 \%)$ & $<0.001$ \\
\hline Bakri Balloon & $11(2.5 \%)$ & $5(3.4 \%)$ & $6(2.1 \%)$ & 0.417 \\
\hline Cervical repair & $1(0.2 \%)$ & $0(0 \%)$ & $1(0.3 \%)$ & 1.00 \\
\hline Vaginal repair & $107(24.4 \%)$ & $21(14.1 \%)$ & $86(29.8 \%)$ & $<0.001$ \\
\hline Vaginal packing & $2(0.5 \%)$ & $1(0.7 \%)$ & $1(0.3 \%)$ & 1.00 \\
\hline Vaginal haematoma drainage & $2(0.5 \%)$ & $0(0 \%)$ & $2(0.7 \%)$ & 0.55 \\
\hline Uterine artery ligation & $1(0.2 \%)$ & $0(0 \%)$ & $1(0.3 \%)$ & 1.00 \\
\hline Uterine artery embolization & $1(0.2 \%)$ & $1(0.7 \%)$ & $0(0 \%)$ & 0.34 \\
\hline B Lynch suture insertion & $1(0.2 \%)$ & $0(0 \%)$ & $1(0.3 \%)$ & 1.00 \\
\hline Hysterectomy & $1(0.2 \%)$ & $1(0.7 \%)$ & $0(0 \%)$ & 0.34 \\
\hline Surgical intervention with early BCE $(n=104)$ versus late BCE $(n=45)$ & - & $16(15.4 \%) 13(28.9 \%)$ & - & 0.009 \\
\hline Blood loss (mean in $\mathrm{mL}$ ) & 1626.0 & 1633.3 & 1622.3 & 0.86 \\
\hline Blood transfusion (packed cell unit) & 2.5 & 2.6 & 2.5 & 0.71 \\
\hline Lowest postpartum haemoglobin (g/L) & 94.4 & 93.3 & 95.0 & 0.36 \\
\hline
\end{tabular}

${ }^{1}$ Continuous variables were assessed by the t-test and categorical variables were analysed using the chi-squared test. $P$ value of $<0.05$ is considered statistically significant 
Table 3 Uterotonic drug usage and usage of BCE

\begin{tabular}{lllll}
\hline & Total cohort $(n=438)$ & BCE performed $(n=149)$ & BCE not performed $(n=289)$ & $p$ value \\
\hline Oxytocin infusion & $432(98.6 \%)$ & $149(100 \%)$ & $283(97.9 \%)$ & 0.10 \\
Ergometrine & $290(66.2 \%)$ & $127(85.2 \%)$ & $163(56.4 \%)$ & $<\mathbf{0 . 0 0 1}$ \\
Ergometrine-additional dose & $135(30.8 \%)$ & $76(51.0 \%)$ & $59(20.4 \%)$ & $<\mathbf{0 . 0 0 1}$ \\
Misoprostol & $186(42.5 \%)$ & $93(62.4 \%)$ & $93(32.2 \%)$ & $<0.001$ \\
PgF2a & $10(2.3 \%)$ & $8(5.4 \%)$ & $2(0.7 \%)$ & $\mathbf{0 . 0 0 4}$
\end{tabular}

${ }^{1}$ Continuous variables were assessed by the t-test and categorical variables were analysed using the chi-squared test. $P$ value of $<0.05$ is considered statistically significant

$\mathrm{g} / \mathrm{L} ; p=0.015)$ whereas it did not have the same effect in those who did not receive BCE $(94.5$ vs $98.0 \mathrm{~g} / \mathrm{L} ; p=$ 0.482).

\section{Discussion}

Our findings suggest that, among women who experience severe PPH after vaginal delivery, BCE may be associated with a lower risk of operating theatre utilisation (OR 0.38; 95\%CI 0.20-0.72; $p=0.003$ ). Despite no associated reduction in total blood loss, need for blood transfusion, lowest $\mathrm{Hb}$ level or use of uterotonic medications (the secondary outcomes), these are highly relevant findings given the potential for adverse surgical consequences. However, these adverse consequences including direct procedural complications, disruption of the newly formed family unit and financial factors were not directly addressed in this work. Surgical interventions for $\mathrm{PPH}$ include uterine cavity tamponade, compression sutures, uterine or internal iliac artery ligation, and hysterectomy; all recommended worldwide [16-20], each with potential complications.

Ergometrine, Misoprostol and PgF2 $\alpha$ were used more in the BCE group. This may reflect the severity of uterine atony, necessitating the use of BCE and all uterotonic agents, or that, having emptied the uterus, the treating clinician was more confident to continue treating with uterotonics rather than resorting to surgical intervention. Reduced blood loss when oxytocin infusion was given after $\mathrm{BCE}$, and higher postpartum haemoglobin level when misoprostol was administered after BCE, illustrate how emptying the uterus allows medications to work more effectively on the myometrium. The use of the specific uterotonics was also in accordance with the current PPH local operating procedures within our institution throughout the study period. This did not include the use of tranexamic acid; which was not used at this time. However, at time of writing of this manuscript, we have released a new guideline in accordance with the updated NSW Health Policy Directive which involved early use of tranexamic acid (TXA), prior to PgF2 $\alpha$. Average times for medical officer attendance was after delivery was significantly higher in the BCE group. We acknowledge the potential that later review may preference cases more refractory to strategies other than $\mathrm{BCE}$, which was generally initiated following medical officer attendance.

Of 132 patients with surgical haemostasis, 35\% had uterine evacuation, $49 \%$ needed MROP and $81 \%$ required repair of genital tract trauma, illustrating the coexistence of multiple aetiological factors. The non-BCE group required statistically significantly more MROP. In the setting of retained placenta, clinical practice would be to proceed directly to the operating theatre for manual removal of the placenta, rather than undergoing additional examination in the delivery suite room for BCE. The reason for this is that $\mathrm{BCE}$ in the setting of retained placenta could not be a definitive therapy. The finding of more tear repairs in the non-BCE group likely reflects that in those cases, genital tract trauma was thought to be the main contributor of the bleeding, hence BCE was not performed.

Although we could find no published literature relating BCE with subsequent need for surgery, a French population-based study looking at components of $\mathrm{PPH}$ management showed that delaying bimanual uterine examination by more than $20 \mathrm{~min}$ after delivery increased the risk of severe PPH by 1.8 times, compared to performing it within $10 \mathrm{~min}$ of delivery [21]. The published literature on severe PPH mostly comprises retrospective audits assessing outcomes and complications of surgical interventions with sample sizes less than 200 [20-24]. The current study is a substantial single tertiary centre retrospective study on management and outcome of severe $\mathrm{PPH}$, providing detailed information on maternal, pregnancy, labour and postpartum characteristics. Epidemiological studies have found a temporal increase in $\mathrm{PPH}$ analysing data from large perinatal databases, lacking detailed information on the management of labour [25].

There are several limitations to our current study. A theoretical disadvantage of this single center study is that, despite the use of a single robust state-wide database for all obstetrical outcomes, it relies on precise data input by staff; as is the case for the bulk of such retrospective studies. However, this effect is unlikely to be significant given the extensive cross-referencing between 
the medical files and the obstetric database during data collection. As with all minor procedures, we cannot exclude the possibility that BCE were performed but not documented, though, given the invasive nature of this procedure and the contemporary culture for informed consent and documentation, we consider this unlikely. Lowest postpartum haemoglobin was used as a marker for blood loss, given the unreliable nature of visual blood loss estimation. We acknowledge the potential for overestimation of blood loss occurring with excessive intravenous fluid administration. Collector bags used in certain European countries to accurately quantify the amount of blood loss [26], are not available in our institution. We acknowledge also that with this retrospective evaluation we were not able to determine at what stage of blood loss BCE was performed, and whether the comparator group received non-BCE intervention at an equivalent stage of bleeding. This is a deficiency that could be addressed in further prospective evaluation. Our paper includes several secondary outcomes and we acknowledge the potential for type 1 error. Therefore these need to be interpreted with caution, warranting further prospective evaluation. As this study was retrospective, we were not able to gain information regarding the contemporaneous skill and experience at performing $\mathrm{BCE}$ of the medical operators managing these cases of PPH. This should also be the subject of future evaluation.

Endometritis and patient discomfort due to bimanual examination were not formally assessed. In our institution, prophylactic intravenous antibiotics were routinely administered after BCE to prevent infection. Future studies could assess the complications of bimanual examination and the associated patient perspectives, particularly in those without epidural anaesthesia. Other limitations of the study are intrinsic to its retrospective design and single centre nature, potentially limiting external applicability, requiring further prospective evaluation.

\section{Conclusion}

We believe this study to be the first evaluating the impact of BCE on management of severe $\mathrm{PPH}$, showing an associated reduced need for surgical intervention. The data generated could form the basis for a prospective randomised controlled trial to more clearly delineate the role of BCE in management of severe PPH. Should this effect be consistent, we would recommend incorporation of BCE into PPH management algorithms; being a simple first line intervention with the potential to reduce the need for surgical intervention. Further prospective studies are indicated to clarify its role in clinical management and any potential complications.

\section{Supplementary information}

Supplementary information accompanies this paper at https://doi.org/10. 1186/s12884-020-02916-w.

Additional file 1. Uterotonic drugs- first and additional doses. *1st Oxytocin dose $=10$ units IM; Additional dose $=$ Oxytocin 10 units/hour intravenous infusion. 4/5 who did not receive Oxytocin IM was given Oxytocin infusion.. **PGF2a dose $=3 \mathrm{mg}$

\section{Abbreviations}

ACOG: The American Congress of Obstetricians and Gynecologists; BCE: Bimanual clot evacuation; Hb: Haemoglobin; MROP: Manual removal of placenta; PPH: Postpartum haemorrhage; RCOG: Royal College of Obstetricians and Gynaecologists; RANZCOG: Royal Australian and New Zealand College of Obstetricians and Gynaecologists; SOGC: The Society of Obstetricians and Gynaecologists of Canada

\section{Acknowledgements}

The authors would like to thank the medical records department staff for medical file retrieval, Mr. Martin Lau (statistician) and Associate Professor Andrew Bisits for analysing the data, and Ms. Virginia Spear for providing support on 'ObstetriX' data.

\section{Authors' contributions}

The study was planned jointly by AW, PRK and AB. PRK and DDF collected the data. All co-authors contributed to the manuscript. All authors have read and approved the manuscript.

\section{Funding}

This was not involved in the study.

\section{Availability of data and materials}

The dataset used and analysed during this study is available from the authors on reasonable request.

\section{Ethics approval and consent to participate}

Ethics approval was obtained from the South Eastern Sydney Local Health District Ethics Review Committee (13/076-LNR 13/POWH/418) on November 13, 2013. Individual informed consent for participants was not required.

Consent for publication

Not applicable.

\section{Competing interests}

The authors declare that they have no competing interests.

\section{Author details}

'School of Women's and Children's Health, University of New South Wales, Randwick, NSW, Australia. ${ }^{2}$ Department of Obstetrics, Royal Hospital for Women, Sydney, NSW, Australia. ${ }^{3}$ Department of Maternal-Fetal Medicine, Royal Hospital for Women, Locked Bag 2000, Barker Street, Randwick, NSW 2031, Australia.

Received: 30 November 2019 Accepted: 30 March 2020 Published online: 25 April 2020

\section{References}

1. World Health Organization. International statistical classification of disease and related health problems. 10th ed. Geneva: World Health Organization; 2010.

2. Say L, Chou D, Gemmill A, Tuncalp O, Moller AB, Daniels J, et al. Global causes of maternal death: a WHO systematic analysis. Lancet Glob Health. 2014;2(6):e323-33.

3. Committee on Practice Bulletins-Obstetrics. Practice Bulletin No. 183: Postpartum Hemorrhage. Obstet Gynecol. 2017;130(4):e168-e86.

4. Henry A, Birch MR, Sullivan EA, Katz S, Wang YA. Primary postpartum haemorrhage in an Australian tertiary hospital: a case-control study. Aust N Z J Obstet Gynaecol. 2005:45(3):233-6.

5. Marasinghe JP, Du Plessis J, Epitawela D, Umstad MP. Management of postpartum haemorrhage with uterine balloon tamponade: the way forward. Aust N Z J Obstet Gynaecol. 2015;55(4):315-7. 
6. van Stralen $\mathrm{G}$, von Schmidt Auf Altenstadt JF, Bloemenkamp KW, van Roosmalen J, Hukkelhoven CW. Increasing incidence of postpartum hemorrhage: the Dutch piece of the puzzle. Acta Obstet Gynecol Scand. 2016:95(10):1104-10.

7. Knight M, Callaghan WM, Berg C, Alexander S, Bouvier-Colle MH, Ford JB, et al. Trends in postpartum hemorrhage in high resource countries: a review and recommendations from the International Postpartum Hemorrhage Collaborative Group. BMC Pregnancy Childbirth. 2009;9:55.

8. Kramer MS, Berg C, Abenhaim H, Dahhou M, Rouleau J, Mehrabadi A, et al. Incidence, risk factors, and temporal trends in severe postpartum hemorrhage. Am J Obstet Gynecol. 2013;209(5):449.e1-7.

9. Andersen H, Hopkins M. Postpartum hemorrhage. In: The global library of Women's medicine. London: David G T Bloomer; 2008. [cited 16/10/2017]. Available from: http://www.glowm.com/section_view/heading/ Postpartum\%20Hemorrhage/item/138

10. Dahlke JD, Mendez-Figueroa H, Maggio L, Hauspurg AK, Sperling JD, Chauhan SP, et al. Prevention and management of postpartum hemorrhage: a comparison of 4 national guidelines. Am J Obstet Gynecol. 2015;213(1):76.e1-10

11. SOGC. Prevention and management of postpartum Haemorrhage. J SOGC 2000;22(4):271-81.

12. Hofmeyr GJ, Abdel-Aleem H, Abdel-Aleem MA. Uterine massage for preventing postpartum haemorrhage. Cochrane Database Syst Rev. 2013;7: CD006431.

13. Saccone G, Caissutti C, Ciardulli A, Abdel-Aleem H, Hofmeyr GJ, Berghella V. Uterine massage as part of active management of the third stage of labour for preventing postpartum haemorrhage during vaginal delivery: a systematic review and meta-analysis of randomised trials. BJOG. 2018;125(7):778-81.

14. Bose P, Regan F, Paterson-Brown S. Improving the accuracy of estimated blood loss at obstetric haemorrhage using clinical reconstructions. BJOG. 2006;113(8):919-24.

15. Dildy GA 3rd, Paine AR, George NC, Velasco C. Estimating blood loss: can teaching significantly improve visual estimation? Obstet Gynecol. 2004; 104(3):601-6.

16. Mousa HA, Alfirevic Z. Treatment for primary postpartum haemorrhage. Cochrane Database Syst Rev. 2007;1:Cd003249.

17. ACOG. Practice bulletin: clinical management guidelines for obstetriciangynecologists number 76, October 2006: postpartum hemorrhage. Obstet Gynecol. 2006;108(4):1039-47.

18. RCOG. Placenta Praevia, placenta Praevia Accreta and vasa Praevia:diagnosis and management (green-top guideline no. 27). Revised October 2005 ed. London: RCOG; 2001.

19. d'Ercole C, Sjojai R, Desbriere R, Cravello L, Boubli L. Surgical management of primary postpartum hemorrhage. J Gynecol Obstet Biol Reprod. 2004;33: 4S103-19.

20. Sentilhes L, Gromez A, Clavier E, Resch B, Verspyck E, Marpeau L. Fertility and pregnancy following pelvic arterial embolisation for postpartum haemorrhage. BJOG. 2010;117(1):84-93.

21. Driessen M, Bouvier-Colle M, Dupont C, Khoshnood B, Rudigoz R, DeneuxTharaux C. Postpartum hemorrhage resulting from uterine atony after vaginal delivery: factors associated with severity. Obstet Gynaecol. 2011;117 (1):21-31.

22. Poujade O, Grossetti A, Mougel L, Ceccaldi PF, Ducarme G, Luton D. Risk of synechiae following uterine compression sutures in the management of major postpartum haemorrhage. BJOG. 2011;118(4):433-9.

23. Joshi VM, Otiv SR, Majumder R, Nikam YA, Shrivastava M. Internal iliac artery ligation for arresting postpartum haemorrhage. BJOG. 2007;114(3):356-61.

24. Jones B, Zhang E, Alzouebi A, Robbins T, Paterson-Brown S, Prior T, et al. Maternal and perinatal outcomes following peripartum hysterectomy from a single tertiary Centre. Aust N Z J Obstet Gynaecol. 2013;53(6):561-5.

25. Lisonkova S, Mehrabadi A, Allen VM, Bujold E, Crane JM, Gaudet L, et al. Atonic postpartum hemorrhage: blood loss, risk factors, and third stage management. J Obstet Gynaecol Can. 2016;38(12):1081-90.e2.

26. Zhang WH, Deneux-Tharaux C, Brocklehurst P, Juszczak E, Joslin M, Alexander $\mathrm{S}$, et al. Effect of a collector bag for measurement of postpartum blood loss after vaginal delivery: cluster randomised trial in 13 European countries. BMJ. 2010;340:c293

\section{Publisher's Note}

Springer Nature remains neutral with regard to jurisdictional claims in published maps and institutional affiliations.

Ready to submit your research? Choose BMC and benefit from:

- fast, convenient online submission

- thorough peer review by experienced researchers in your field

- rapid publication on acceptance

- support for research data, including large and complex data types

- gold Open Access which fosters wider collaboration and increased citations

- maximum visibility for your research: over $100 \mathrm{M}$ website views per year

At BMC, research is always in progress.

Learn more biomedcentral.com/submissions 